\title{
First feedback with the AMMON integral experiment for the JHR calculations
}

\author{
C. Vaglio-Gaudard ${ }^{1, \mathrm{a}}$, O. Leray ${ }^{1}$, M. Lemaire ${ }^{1}$, A.C. Colombier ${ }^{1}$, J.P. Hudelot ${ }^{1}$ \\ ${ }^{1}$ CEA, DEN, DER/SPRC/LPN, Cadarache, F-13108 Saint Paul les Durance, France
}

\begin{abstract}
The innovative design of the next international Material Testing Reactor, the Jules Horowitz Reactor (JHR), induced the development of a new neutron and photon calculation formular HORUS3D/P\&N, based on deterministic and stochastic codes and the European nuclear data library JEFF3.1.1. A new integral experiment, named the AMMON experiment, was designed in order to make the experimental validation of HORUS3D. The objectives of this experimental program are to calibrate the biases and uncertainties associated with the HORUS3D/N\&P calculations for JHR safety and design calculations, but also the validation of some specific nuclear data (concerning mainly hafnium and beryllium isotopes). The experiment began in 2010 and is currently performed in the EOLE zero-power critical mock-up at CEA Cadarache. This paper deals with the first feedback of the AMMON experiments with 3D Monte Carlo TRIPOLI4C/JEFF3.1.1 calculations.
\end{abstract}

\section{Introduction}

The innovative design of the next international Material Testing Reactor, the Jules Horowitz Reactor (JHR), induced the development of a new neutron and photon calculation formular HORUS3D/P\&N [1], based on deterministic and stochastic codes and the European nuclear data library JEFF3.1.1. The core is composed of about 30 fuel elements of circular shape, cooled and moderated with light water. They are inserted into an aluminium alloy rack and arranged in an irregular "daisy flower"shaped pattern. Each fuel element is a set of $\mathrm{U}_{3} \mathrm{Si}_{2}-\mathrm{Al}\left(\mathrm{e} \%{ }^{235} \mathrm{U} \geq 19.75 \%\right)$ curved plates assembled with stiffeners. A beryllium reflector surrounds the core.

A new integral experiment, named the AMMON experiment [2], was designed in order to make the experimental validation of the HORUS3D calculation scheme. The objectives of this experimental program are to calibrate the biases and uncertainties associated with the HORUS3D/N\&P calculations for JHR safety and design calculations, but also the validation of some specific nuclear data (concerning mainly hafnium and beryllium isotopes). The experiment began in 2010 and is currently performed in the EOLE zero-power critical mock-up at CEA Cadarache. Several configurations are foreseen for the 2-year experimental program.

\footnotetext{
a claire.vaglio-gaudard@cea.fr
} 
After a brief description of the AMMON experiment, some results concerning the interpretation of the reference, hafnium and beryllium configurations are presented and commented in this paper.

\section{Description of the AMMON experiment}

The AMMON experiment (Fig. 1) consists of an experimental zone dedicated to the analysis of the JHR neutron physics surrounded by a driver zone loaded in the EOLE facility. Several configurations are foreseen in the program, which impacts the loading of the experimental zone.

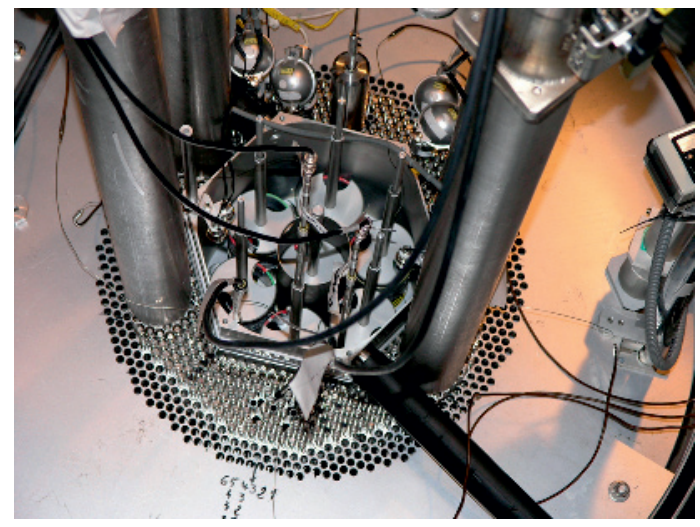

Fig. 1. AMMON/REF experiment in the EOLE experimental reactor

The experimental zone of the reference configuration contains 7 JHR standard assemblies inserted in an aluminium alloy hexagonal rack $(30 \mathrm{~cm}$ side length). The central standard assembly of the reference configuration can be replaced by another element (Fig. 2), such as an assembly with an hafnium rod inserted or half inserted, a beryllium block, a voided assembly or a cavity filled with water, in the other configurations.

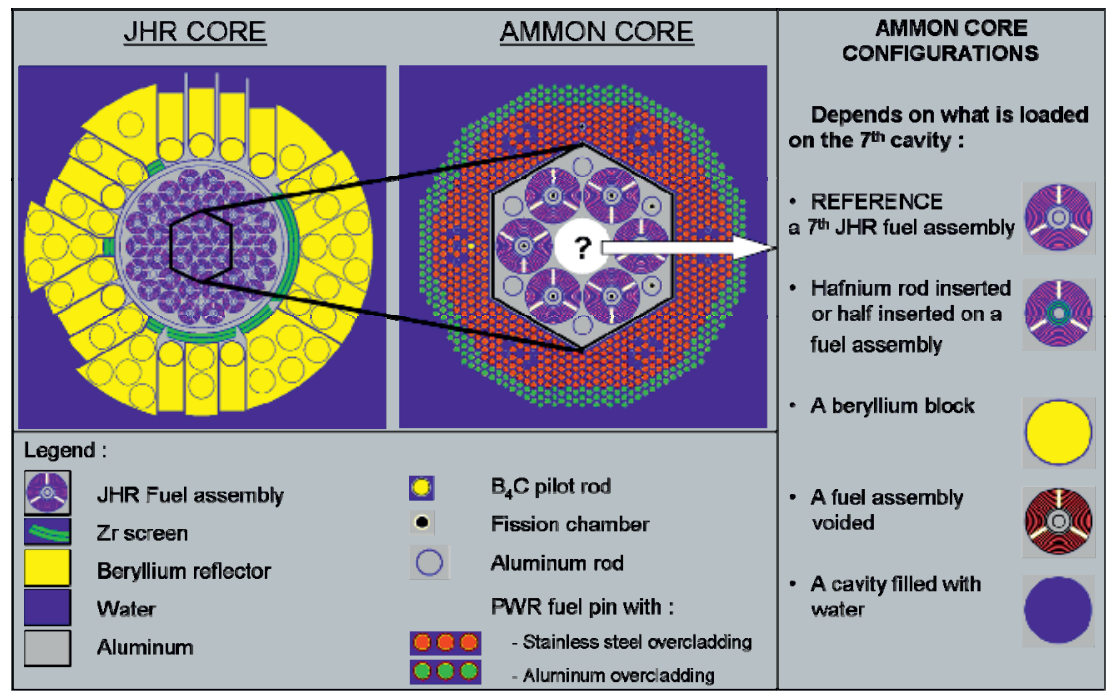

Fig. 2. The different configurations in the AMMON experimental program 
The JHR fuel assembly is composed of $3 \times 8$ cylindrical fuel plates, maintained by 3 aluminium alloy stiffeners. The external diameter of the assembly is about $10 \mathrm{~cm}$ for a $60-\mathrm{cm}$ active length. The fuel plates are composed of $\mathrm{U}_{3} \mathrm{Si}_{2}-\mathrm{Al}$ fuel (with a $27 \%{ }^{235} \mathrm{U}$ enrichment) and $\mathrm{Al}-\mathrm{Fe}-\mathrm{Ni}$ cladding.

The central cavity of the assembly hosts an aluminium absorber rod follower. Besides, 6 fillers are also inserted in the rack between fuel assemblies. The followers and fillers can be instrumented with neutron and gamma detectors.

The driver zone is composed of standard PWR 3.7\% ${ }^{235} \mathrm{U}$ enriched $\mathrm{UO}_{2}$ fuel pins, with Zircaloy-4 cladding, and stainless steel or aluminium (it depends of the configuration) overcladding. The hexagonal lattice pitch of the driver pins was optimized in order to reproduce as well as possible the same neutron spectrum as the one of the experimental zone.

\section{Some interpretation results}

The analysis of the AMMON experimental program [5] is currently in progress, with reference three-dimensional core calculations using the continuous-energy Monte Carlo TRIPOLI4C code and the JEFF3.1.1 nuclear data library processed at room temperature. Some results concerning the preliminary analysis of the residual reactivity and reactivity worth are presented below for the reference configuration (AMMON/REF) and the configurations with respectively an hafnium rod completely inserted (AMMON/Hf) in the fuel central assembly and a beryllium block $(\mathrm{AMMON} / \mathrm{Be})$ at the core center.

The criticality of the AMMON cores is adjusted through the number of fuel pins inserted in the driver zone. The residual reactivity is controlled by the insertion of the automatic pilot rod (one $\mathrm{B}_{4} \mathrm{C}$ rod). The calculation-experiment (C-E) comparison for the residual reactivity is shown in Table I.

Table 1. AMMON residual reactivity

\begin{tabular}{|c|c|c|c|}
\hline AMMON configuration & REF & Hf & Be \\
\hline Measurement & $+184 \mathrm{pcm} \pm 9^{\mathrm{a}}$ & $+212 \mathrm{pcm} \pm 11^{\mathrm{a}}$ & $+155 \mathrm{pcm} \pm 8^{\mathrm{a}}$ \\
\hline TRIPOLI4 & $+560 \mathrm{pcm} \pm 3^{\mathrm{b}}$ & $+573 \mathrm{pcm} \pm 2^{\mathrm{b}}$ & $+521 \mathrm{pcm} \pm 2^{\mathrm{b}}$ \\
\hline C-E & $+376 \mathrm{pcm}$ & $+361 \mathrm{pcm}$ & $+366 \mathrm{pcm}$ \\
\hline \multicolumn{4}{|c}{} \\
\multicolumn{3}{|c|}{${ }^{\mathrm{a}}$ Experimental uncertainty $(1 \sigma)$} \\
\end{tabular}

The technological uncertainty associated with the (C-E) value on reactivity is about $340 \mathrm{pcm}$ $(1 \sigma)$ for all the configurations.

The Keff calculation of the AMMON cores is satisfactory regarding the uncertainty due to nuclear data: in particular, concerning the reference configuration $\mathrm{C}-\mathrm{E}=+376 \pm 340(1 \sigma) \mathrm{pcm}$. Indeed, a rigorous nuclear data uncertainty propagation on reactivity provides $671 \mathrm{pcm}[6](1 \sigma)$ uncertainty (360 pcm uncertainty comes only from ${ }^{27} \mathrm{Al}$ nuclear data).

The bias due to nuclear data on the AMMON calculated reactivity is transposed to JHR thanks to the representativity methodology [7]. This methodology lies on the calculation of the propagation of a priori nuclear data uncertainties on the reactivity parameter, to highlight the representativity of the AMMON experiment with JHR and to determine the final bias associated with the JHR reactivity calculation $(+250 \mathrm{pcm} \pm 328)$. This methodology needs realistic covariance matrices: the JEFF3.1.1 matrices were used, and a specific work [6] was performed to define a realistic ${ }^{27} \mathrm{Al}$ covariance matrix (the matrix is missing in the JEFF3.1.1 evaluation). 
In order to quantify the calculation bias on the reactivity worth of the hafnium rod and the beryllium block, the calculation biases obtained on the reactivity of the reference configuration and the perturbed configurations (presence of hafnium or / beryllium), which are critical states, are compared, as below:

$$
\delta \Delta \rho=\Delta \rho_{\text {calc }}-\Delta \rho_{\text {mes }}=\left(\rho_{\text {calc }}^{H f / B e}-\rho_{\text {calc }}^{R E F}\right)-\left(\rho_{\text {mes }}^{H f / B e}-\rho_{\text {mes }}^{R E F}\right)
$$

with $\rho_{\text {calc }}^{x}$ being the calculated residual reactivity and $\rho_{\text {mes }}^{x}$ the measured residual reactivity for a given configuration $\mathrm{x}$.

The reactivity worth of the hafnium rod and the beryllium block is determined experimentally, which enables to present the calculation relative bias:

$$
\frac{\delta \Delta \rho}{\Delta \rho}=\frac{\left(\rho_{\text {calc }}^{H f / B e}-\rho_{\text {calc }}^{R E F}\right)-\left(\rho_{\text {mes }}^{H f / B e}-\rho_{\text {mes }}^{R E F}\right)}{\Delta \rho_{\text {mes }}}
$$

Thus, the calculation bias on the hafnium rod and beryllium block with TRIPOLI4C/JEFF3.1.1 is given on Table 2 for the AMMON experiment.

Table 2. Hafnium and beryllium reactivity worth

\begin{tabular}{|l|c|c|}
\hline AMMON configuration & Hf & Be \\
\hline Experimental worth & $-3356 \mathrm{pcm}$ & $-2526 \mathrm{pcm}$ \\
\hline (C-E)/E & $+0.5 \% \pm 1.8 \%$ & $+0.4 \% \pm 2.0 \%$ \\
\hline
\end{tabular}

The uncertainties associated with the (C-E)/E values gather the experimental uncertainty, the technological uncertainty and the uncertainty due the reactivity worth calculation of the fuel pins introduced in order to compensate the negative reactivity of the hafnium rod or beryllium block.

A good agreement between Calculation and Experiment can be noticed for the reactivity worth calculation: the (C-E)/E values are within the uncertainty at one standard deviation. These results enable to extend the qualification field for the evaluation of JEFF3.1.1 hafnium isotopes for a hard LWR neutron spectrum comparing to the other experiments in the EOLE facility [5]. Very few elements are available concerning the qualification of the JEFF3.1.1 beryllium evaluation: this work brings one element qualification for the beryllium reactivity worth calculation in a LWR spectrum.

\section{Conclusion}

The AMMON experiment was designed in the EOLE zero-power facility in order to qualify the calculation formular dedicated the design and safety studies for JHR. Some qualification elements are given in this paper from the nuclear data point of view. The bias due to nuclear data on the AMMON/REF reactivity is $+376 \pm 340(1 \sigma)$, which is very satisfactory concerning the a priori nuclear data uncertainty propagation: this result is very important since it made it possible to reduce by a 2 factor the uncertainty associated with the JHR reactivity calculation at the beginning of life of the reactor.

Besides, the hafnium rod efficiency and the reactivity worth of a beryllium block are well predicted with JEFF3.1.1: the (C-E)/E values are within the associated uncertainty. It is the first step of the validation of the beryllium nuclear data: it will be completed by measurements with activation dosimeters performed at the center of the block and at the center of fuel assemblies by the end of 2012. 


\section{Acknowledgments}

The authors are indebted to the members of the operating and experimental team of the EOLE facility for their help, efficiency and professionalism.

\section{References}

1. C. Döderlein, T. Bonaccorsi, C. D’Aletto, J. Di Salvo, O. Gueton, L. Lamoine, F. Moreau, G. Naudan, P. Siréta, "The 3D neutronics scheme for the development of the Jules-Horowitz-Reactor," Proc. Int. Conf. PHYSOR2008, Interlaken, Switzerland, September (2008)

2. J.C. Klein, N. Thiollay, J. Di Salvo, J.C. Bosq, P. Siréta, J.P. Wieryskov, P. Alexandre, D. Garnier, "AMMON: an experimental program in the EOLE critical facility for the validation of the Jules Horowitz Reactor neutron and photon HORUS3D calculation scheme," Proc. Int. Conf. IGORR 2009, Beijing, China, October (2009)

3. E. Brun, E. Dumonteil, F.X. Hugot, N. Huot, C. Jouanne, Y.K. Lee, F. Malvagi, A. Mazzolo, O. Petit, J.C. Trama, A. Zoia, "Overview of TRIPOLI-4C version 7 continuous-energy Monte Carlo transport code," Proc. Int. Conf. ICAPP 2011, Nice, France, May (2011)

4. A. Santamarina et al., "The JEFF-3.1.1 nuclear data library”, NEA, JEFF Report 22 (2009)

5. C. Vaglio-Gaudard, O. Leray, A.C. Colombier, C. D’Aletto, L. Gaubert, O. Gueton, J.P. Hudelot, M. Valentini, P. Siréta, J. Di Salvo, A. Gruel, J.C. Klein, A. Roche, D. Beretz, J.M. Girard, "Monte Carlo interpretation of the AMMON/REF experiment in EOLE for the JHR reactor calculations," Proc. Int. Conf. PHYSOR2012, Knoxville, USA, April (2012)

6. O. Leray, C. Vaglio-Gaudard, J.P. Hudelot, A. Santamarina, G. Noguere, , "Sensitivity and uncertainty analysis applied to the JHR reactivity prediction," Proc. Int. Conf. PHYSOR2012, Knoxville, USA, April (2012)

7. V.V. Orlov, A.A. Van'kov, A.I. Voropaev, Y. A. Kazanskij, V.I. Matveev, V.M. Mugorov, E.A. Khodarev, "Problem of fast reactor physics related to breeding", Atomic Energy Review, 18. 4, pp.989-1077 (1980) 